\title{
Some Novel Tricyclic Caged-Nitramines - A DFT Study
}

\section{Lemi Türker}

Department of Chemistry, Middle East Technical University, Üniversiteler, Eskişehir Yolu No: 1, 06800 Çankaya/Ankara, Turkey; e-mail: 1turker@gmail.com; 1turker@metu.edu.tr

\section{Abstract}

A tricyclic caged-nitramine structure having embedded RDX base has been designed. It also has three etheric linkages in the cage structure. In that sense it reminds TEX structure but it has much better oxygen balance than RDX and TEX. Then two hetero atom exchange operation ( $\mathrm{N}$ to $\mathrm{O}$ replacement) at a time has been carried out to produce different isomeric structures. Through optimization process (B3LYP/6-311++G(d,p)) they have yielded some conformers and stereoisomers. The effect of heteroatom replacement on various geometrical, quantum chemical and spectral properties of the isomers have been investigated and discussed.

\section{Introduction}

Nitramines are important oxidizer ingredients for solid propellants. Note that RDX and HMX are well known nitramines. Nitramines are highly energetic structures and produce high impetus and specific impulse for gun and rocket propulsion systems. Nitramines are molecules which generally produce little smoke, less toxicity and environmental risks.

In the past couple of decades, significant progress has been made in the study of combustion-wave structures and burning characteristics of nitramine type monopropellants such as cyclotrimethylenetrinitramine (RDX) and HMX. Extensive experimental diagnostics [1-3] and theoretical analyses [4-10] were conducted over a broad range of operating conditions.

Received: September 12, 2020; Accepted: October 19, 2020

Keywords and phrases: caged nitramine, nitramine, explosive, TEX, RDX, density functional.

Copyright (C) 2021 Lemi Türker. This is an open access article distributed under the Creative Commons Attribution License, which permits unrestricted use, distribution, and reproduction in any medium, provided the original work is properly cited. 
A comprehensive analysis of laser-induced ignition of 1,3,5-trinitrohexahydro-striazine (RDX) monopropellant has been performed with consideration of detailed chemical kinetics by Liau and coworkers [11].

Substituent effects on the molecular stability, group interaction, detonation performance, and thermolysis mechanism of certain nitramines were reported [12]. On the other hand, design strategy from linear to cyclic to caged molecules were discussed by Yang et al. [13].

The effect of strain on trigger bonds in organic-cage energetic materials, including nitramines was reported [14]. Extension of the research, concentrated on caged nitramines such as TEX and CL-20 have attracted attention in recent years [15-22]. To improve the performance of explosives, the improvement of density is crucial. One way to increase the density is by changing the molecular geometries from linear to cyclic to caged structures. The caged nitramines are much more appealing in seeking high-energy materials [13]. Therefore, the present study is on some novel caged-nitramine structures.

\section{Method of Calculation}

In the present study, the initial structural optimizations of all the structures leading to energy minima have been achieved by using MM2 method followed by PM3 semiempirical self-consistent fields molecular orbital (SCF MO) method [23, 24] at the restricted level $[25,26]$. Subsequent optimizations were achieved at Hartree-Fock level by using various basis sets. Then, the structural optimizations were managed within the framework of density functional theory (DFT) [27, 28] at the level of B3LYP/6$311++G(d, p)[26,29]$. The exchange term of B3LYP consists of hybrid Hartree-Fock and local spin density (LSD) exchange functions with Becke's gradient correlation to LSD exchange $[28,30]$. The correlation term of B3LYP consists of the Vosko, Wilk, Nusair (VWN3) local correlation functional [31] and Lee, Yang, Parr (LYP) correlation correction functional [32]. Also, the vibrational analyses have been done. The total electronic energies are corrected for the zero point vibrational energy (ZPE). The normal mode analysis for each structure yielded no imaginary frequencies for the $3 N-6$ vibrational degrees of freedom, where $N$ is the number of atoms in the system. This indicates that the structure of each molecule corresponds to at least a local minimum on the potential energy surface. All these calculations were done by using the Spartan 06 package program [33]. 


\section{Results and Discussion}

The caged-nitramines usually have desirable high energy and high density e.g., TEX and Cl-20 structures. Therefore in the present computational study some cagednitramines $\left(\mathrm{C}_{4} \mathrm{H}_{4} \mathrm{~N}_{6} \mathrm{O}_{9}\right)$ have been designed and investigated within the realm of density functional theory.

Figure 1 shows the isomeric structures obtained by the simple exchange of two heteroatoms at a time. So, structure-B is from structure-A, structure-C from B etc. As seen in the figure structure-A possesses an embedded RDX (hexogen, cyclonite) structure as its base ring. Whereas structure-E possesses an embedded sym-trioxane ring.
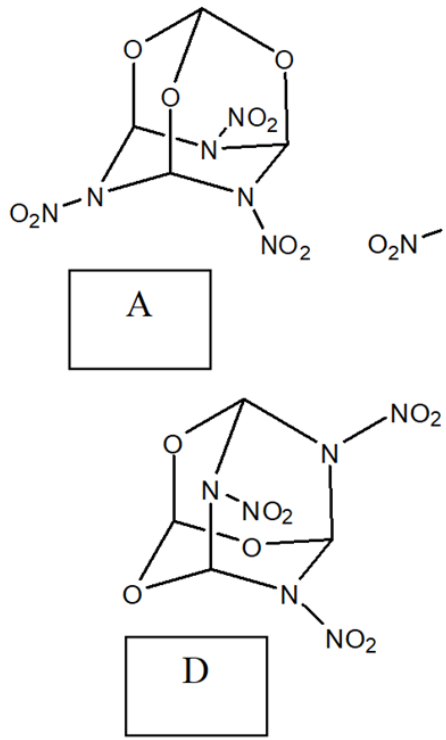

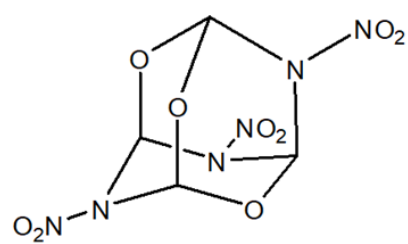

B

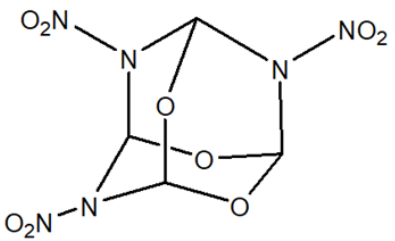

$\mathrm{C}$

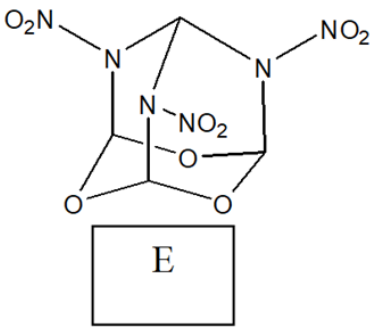

Figure 1. Constitution of the structures presently considered.

Structure-A has three fold symmetry and all the rings are six-membered. So the exchange process of heteroatoms constitutionally may produce the same structure among the group having different appearance. For instance, applying some symmetry operations the constitutional relationship between $\mathrm{A}$ and $\mathrm{D}$ can be shown.

Figure 2 shows the optimized structures of the isomers considered. It also shows the direction of the dipole moment vectors. The optimization process led to different conformers in the case of isomers A and D. Even stereoisomers B and C have been obtained. Figures 3 and 4 display those situations. Structure-A has the nitro groups as all in equatorial positions (eee) whereas structure-D has them in eea conformation. The 
stereoisomers $\mathrm{B}$ and $\mathrm{C}$ are all $\mathrm{R}$ and $\mathrm{S}$ type, respectively. Note that they are diasteromers not enantiomers. These details are not so obvious in Figure 1. Also note that the oxygen balance of these isomers is $-6.34 \%$ whereas RDX and TEX have -21.6 and -42.74 , respectively.
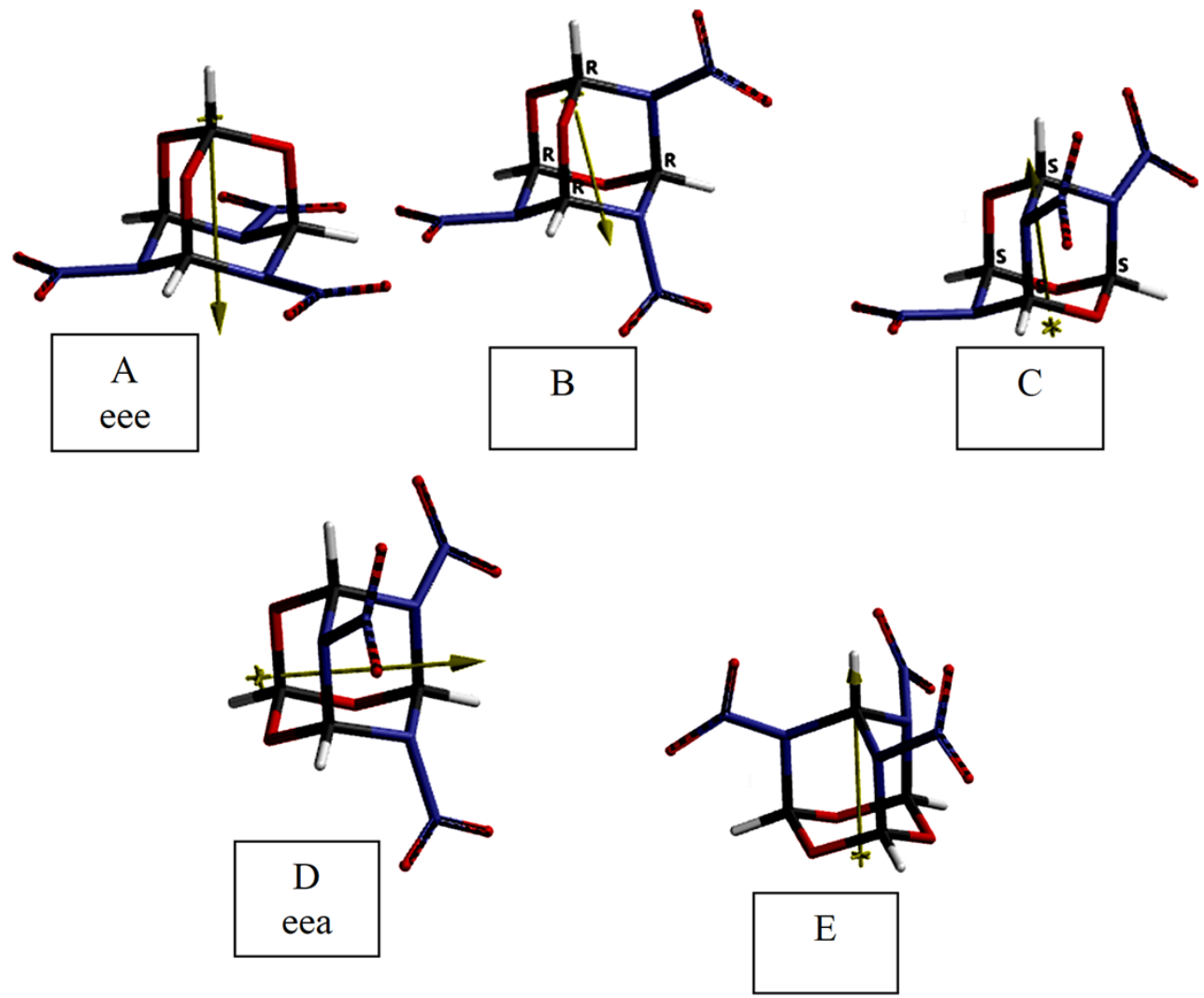

Figure 2. Optimized structures of the isomers considered.
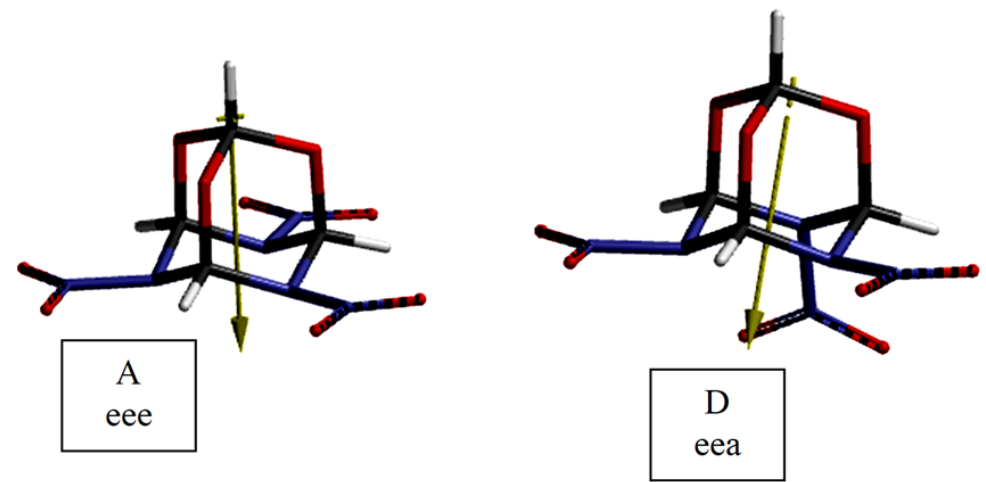

Figure 3. Conformers A and D. 

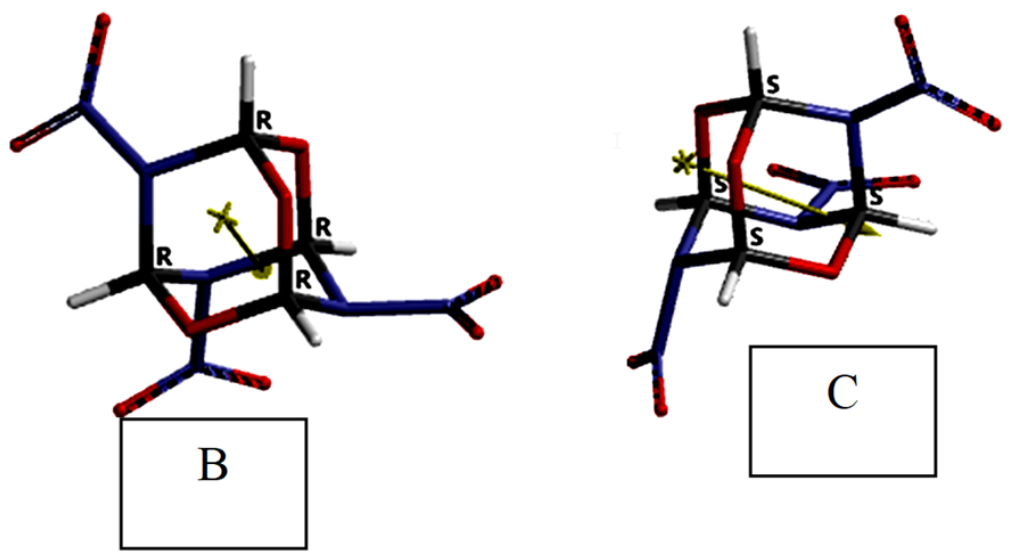

Figure 4. Stereoisomers B and C. They also differ conformationally.

Table 1 lists some properties of structures A through E. Although, some of the values are very comparable, the dipole moments for conformers A and D highly differ. Note that PSA (polarizable surface area) in Table 1 stands for area due to nitrogen and oxygen and any hydrogens attached to nitrogen and oxygen.

Table 1. Some properties of the structures considered.

Structure Area $\left(\AA^{2}\right) \quad$ Volume $\left(\AA^{3}\right) \quad$ Dipole $\quad$ PSA $\left(\AA^{2}\right) \quad$ Polarizability moment

(Debye)

\begin{tabular}{llllll}
\hline A & 208.66 & 182.67 & 0.74 & 153.401 & 54.75 \\
B & 209.32 & 182.89 & 2.12 & 153.394 & 54.74 \\
C & 209.35 & 182.90 & 2.12 & 153.384 & 54.74 \\
D & 209.06 & 182.80 & 2.73 & 153.378 & 54.74 \\
E & 209.20 & 182.85 & 3.15 & 153.319 & 54.72 \\
\hline
\end{tabular}

They all have the Ovality: 1.34, Log P: 4.32 and C1 symmetry.

Assuming that the combustion products of these isomeric structures are the same the heat of combustions of them should be very comparable. Also their densities should be close to each other.

Table 2 shows some energies of the structures considered where E, ZPE and $\mathrm{E}_{\mathrm{C}}$ stand for total electronic energy, zero point vibrational energy and the total corrected 
electronic energy, respectively. The data reveal that they are all stable electronically. Structure E is the most stable among the all. Of the conformers A and D, the later one is more stable.

Table 2. Some energies of the structures considered.

\begin{tabular}{cccc}
\hline Structure & $\mathbf{E}$ & $\mathbf{Z P E}$ & $\mathbf{E}_{\mathbf{C}}$ \\
\hline A & -3046350.98 & 369.83 & -3045981.15 \\
B & -3046347.21 & 370.36 & -3045976.85 \\
C & -3046346.83 & 370.02 & -3045976.81 \\
D & -3046351.35 & 369.93 & -3045981.42 \\
E & -3046351.93 & 370.00 & -3045981.93 \\
\hline
\end{tabular}

Energies in $\mathrm{kJ} / \mathrm{mol}$.

Table 3 shows some thermodynamic values of the structure considered. All the structures considered have exothermic heat of formation values and their formation energies are favorable thermodynamically. Structure $\mathrm{E}$ is the most exothermic and most favorable within the group. Whereas, the stereoisomers B and C are the least exothermic and the least favorable.

Table 3. Some thermodynamic values of the structure considered.

\begin{tabular}{cccc}
\hline Structure & $\mathbf{H}^{\mathbf{0}}(\mathrm{kJ} / \mathrm{mol})$. & $\mathbf{S}^{\mathbf{o}}\left(\mathrm{J} / \mathrm{mol}^{\circ}\right)$ & $\mathbf{G}^{\mathbf{o}}(\mathrm{kJ} / \mathrm{mol})$. \\
\hline A & -3045976.353 & 445.21 & -3046109.100 \\
B & -3045972.126 & 444.84 & -3046104.768 \\
C & -3045972.047 & 445.05 & -3046104.741 \\
D & -3045976.616 & 444.70 & -3046109.205 \\
E & -3045977.167 & 444.76 & -3046109.782 \\
\hline
\end{tabular}

Table 4 shows the heat of formation values calculated based on two different approaches. Of those, T1 method has been developed to closely reproduce heats of formation calculated from G3(MP2). It replaces the large basis set MP2 calculation by a dual basis set R1-MP2 calculation and replaces the QCISD(T) calculation and the vibrational frequency calculation by an empirical correlation based on atom and bond 
counts [33]. As seen in the table, both method of calculations yield parallel sequence of orders. Two extremes isomers, A and E (having base ring of alternating only nitrogen and oxygen substituted, respectively) are the least and most exothermic structures, respectively.

Table 4. $\mathrm{H}^{\mathrm{o}}(\mathrm{kJ} / \mathrm{mol}$.) values of the structures considered.

\begin{tabular}{ccc}
\hline Structure & $\begin{array}{c}\text { PM3//B3LYP/6- } \\
\text { 311++G(d,p) }\end{array}$ & T1 \\
\hline A & -190.040 & -170.67 \\
B & -196.963 & -171.22 \\
C & -197.547 & -171.21 \\
D & -202.217 & -175.46 \\
E & -209.342 & -178.16 \\
\hline
\end{tabular}

Figure 5 displays some of the molecular orbital energy levels of the structures considered. Structures A and D are conformers, therefore their molecular orbital energy spectra are quite similar. Notice the LUMO and NEXTLUMO energy levels of them. On the other hand, $\mathrm{B}$ and $\mathrm{C}$ are stereoisomers (diasteromers), so they exhibit the same pattern.

Table 5 shows the HOMO, LUMO energies and the interfrontier molecular orbital energy gap values $(\Delta \varepsilon)$ of the structures of present concern. Structures-A and $E$ have the smallest and the largest $\Delta \varepsilon$ value, respectively.

Table 5. The HOMO, LUMO energies and $\Delta \varepsilon$ values.

\begin{tabular}{cccc}
\hline Structure & HOMO & LUMO & $\Delta \boldsymbol{\varepsilon}$ \\
\hline A & -908.17 & -317.89 & 590.28 \\
B & -902.89 & -302.16 & 600.73 \\
C & -902.70 & -301.99 & 600.71 \\
D & -906.23 & -308.16 & 598.07 \\
E & -907.19 & -301.79 & 605.40 \\
\hline
\end{tabular}

Energies in $\mathrm{kJ} / \mathrm{mol}$. 

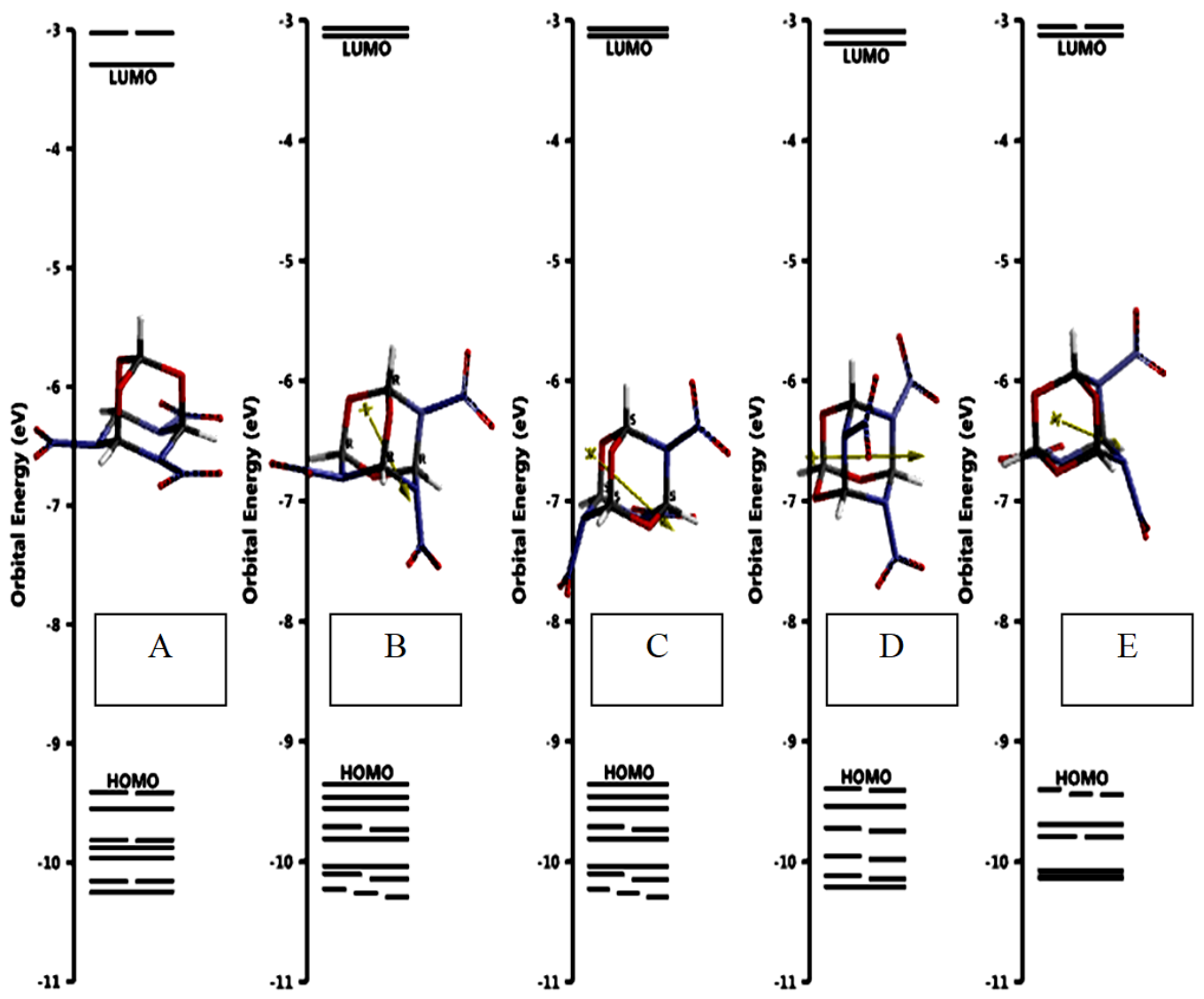

Figure 5. Some molecular orbital energy levels of the isomers.

The time-dependent density functional UV-VIS spectra of the structures produced almost the identical spectra. Figure 6 shows the spectrum of structure-A as a representative one.

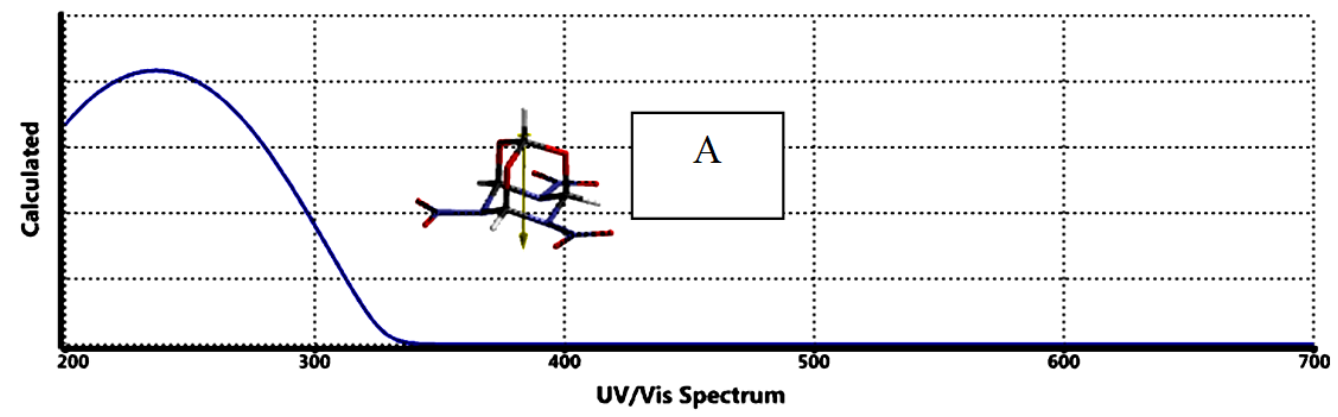

Figure 6. UV-VIS spectra of structure-A. 
Figure 7 shows the HOMO and LUMO patterns of the structures presently considered.

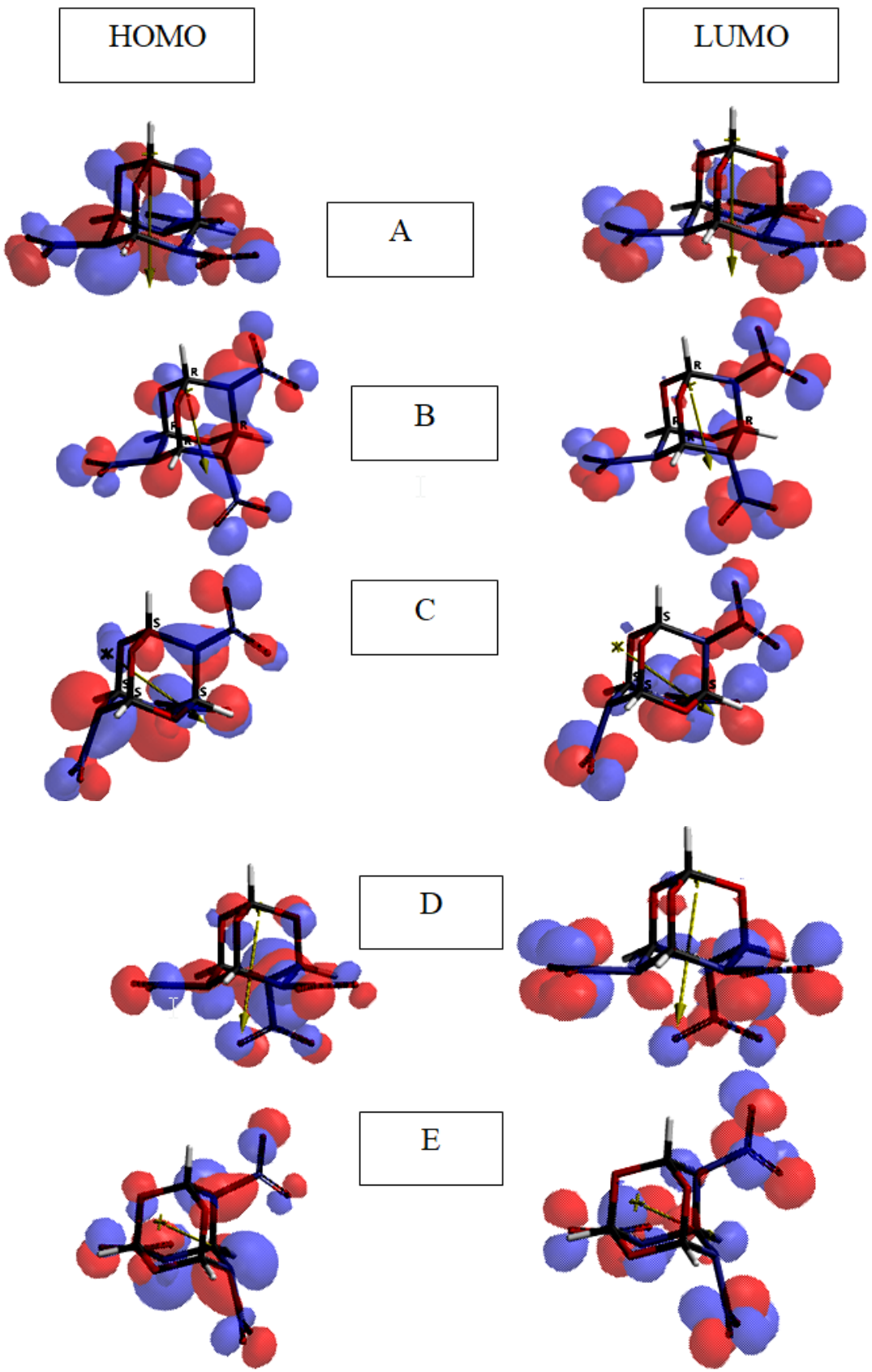

Figure 7. The HOMO and LUMO patterns of the isomers considered. 
Appearance of the electrostatic potential maps of the systems is shown in Figure 8 where red/reddish and blue/green regions stand for negative and positive potential fields, respectively. In the figure, red/yellow regions turns into yellowish/green regions progressively as the nitrogen atoms of structure-A undergo centric perturbations by the oxygen replacement.
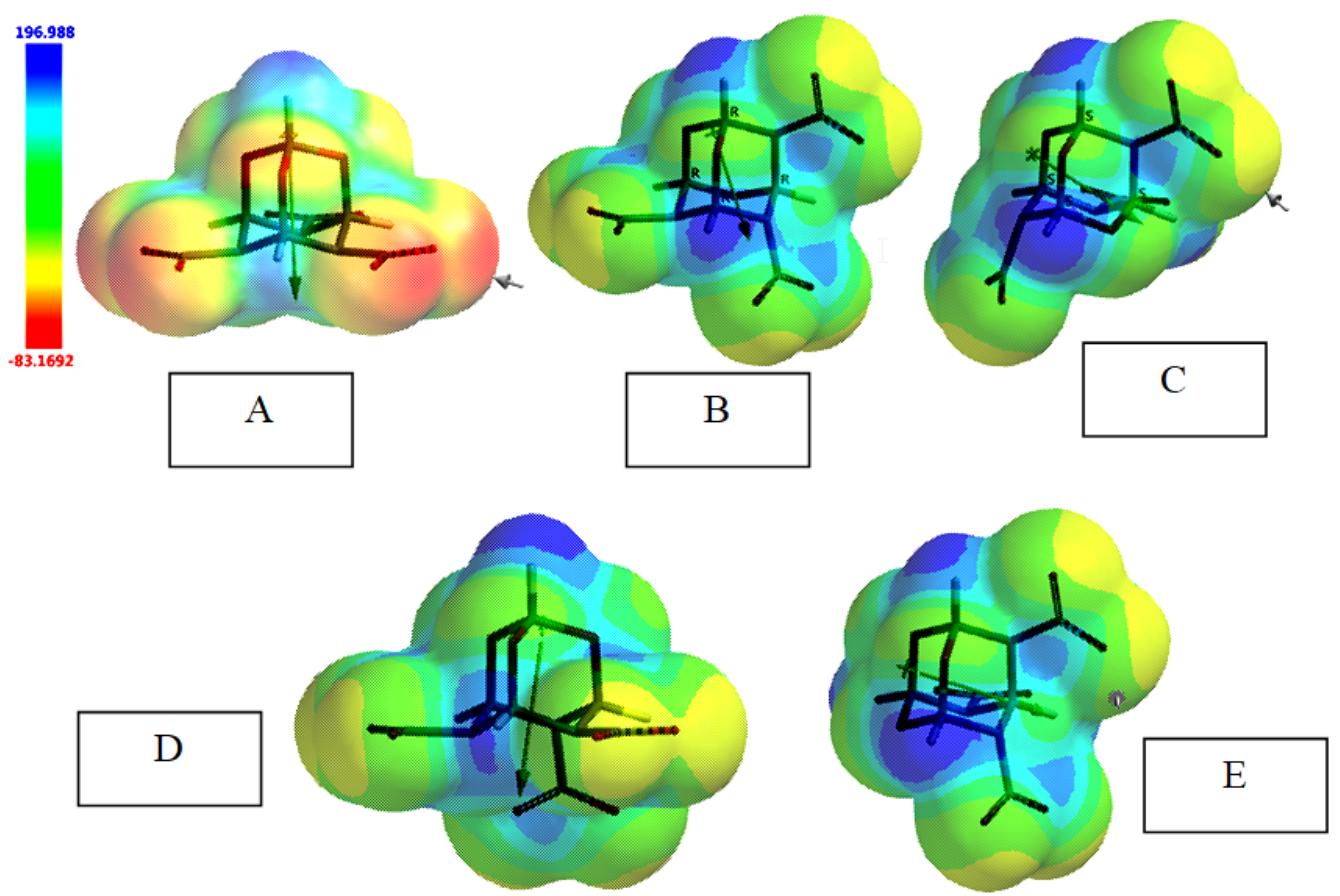

Figure 8. Electrostatic potential maps of the structures considered.

Figure 9 displays the local ionization maps of the structures considered. In the local ionization potential map conventionally red regions on the density surface indicate areas from which electron removal is relatively easy, meaning that they are subject to electrophilic attack. On the other hand, regions having blue color represent areas where ionization is relatively difficult.

Figure 10 stands for the LUMO maps of the structures considered. A LUMO map displays the absolute value of the LUMO on the electron density surface. The blue color stands for the maximum value of the LUMO and the color red, the minimum value. Hence, a nucleophile attacks on the atom having the blue/bluish color. 


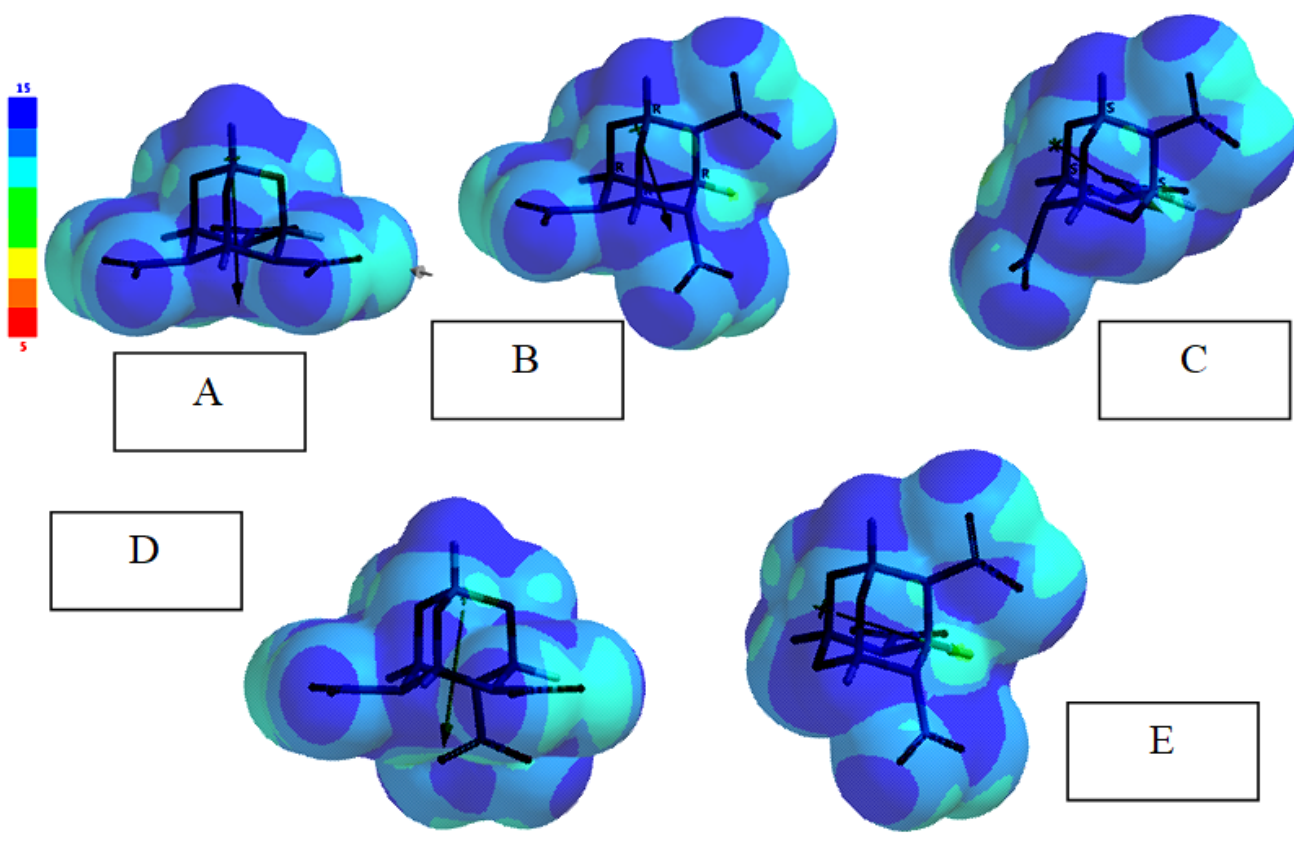

Figure 9. Local ionization maps of the structures considered.
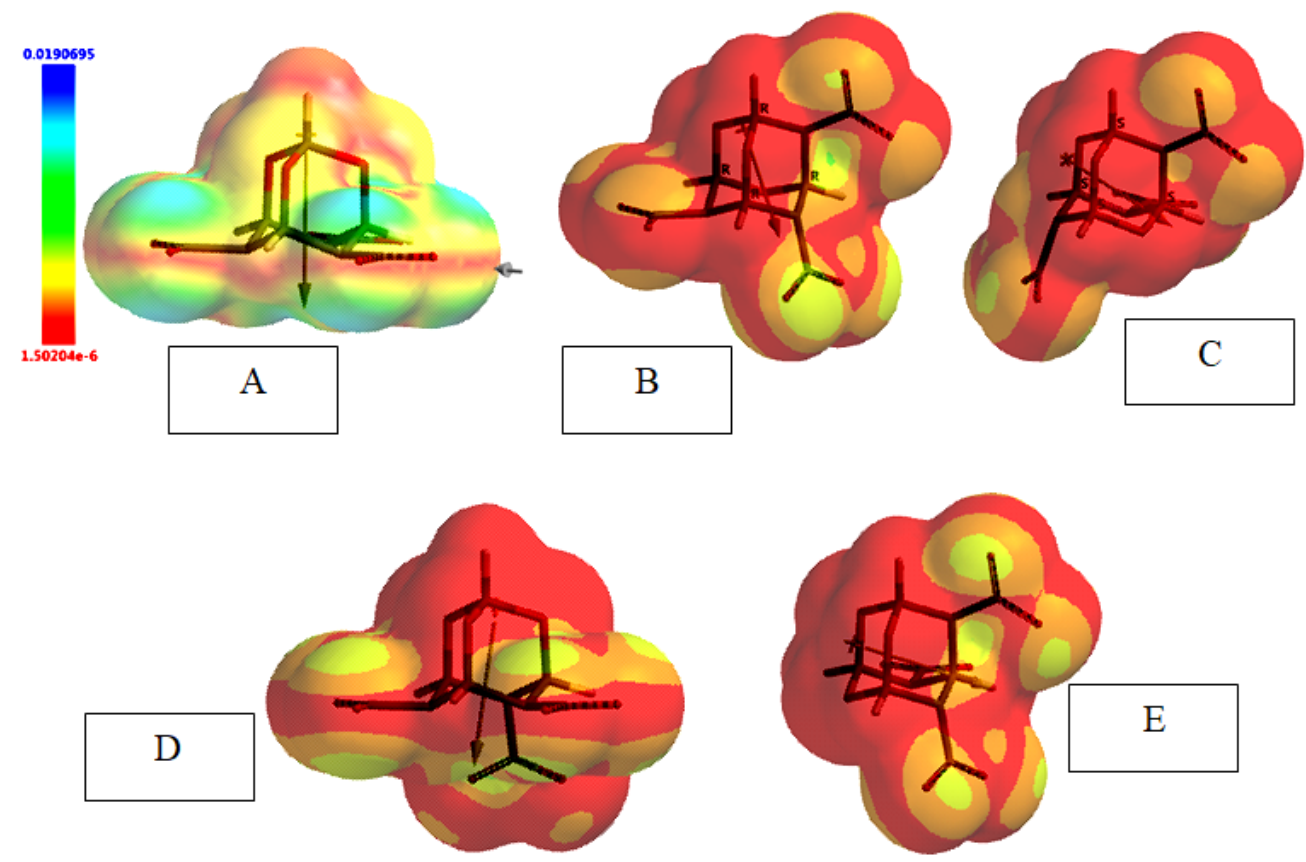

Figure 10. LUMO maps of the structures considered. 


\section{Conclusion}

A novel tricyclic caged-nitramine structure has been designed which possesses an embedded RDX structure and having much better oxygen balance value than RDX and TEX. Various constitutional isomers from that structure have been investigated within the restrictions of density functional theory at the applied level of calculations. They are all exothermic structures and electronically stable ones having favorable free energy of formation values. The cage structure of them suggests that they might have desirable densities preferable for ballistic purposes.

\section{References}

[1] T.P. Parr and D.M. Hanson-Parr, Optical diagnostics of solid propellant flame structure, in: Solid Propellant Chemistry, Combustion, and Motor Interior Ballistics, V. Yang, T. B. Brill, and W. Z. Ren, eds., Vol. 185, Progress in Astronautics and Aeronautics, AIAA, Reston, VA, 2000, pp. 381-411. https://doi.org/10.2514/5.9781600866562.0381.0411

[2] O.P. Korobeinichev, Flame structure of solid propellants, in: Solid Propellant Chemistry, Combustion, and Motor Interior Ballistics, V. Yang, T. B. Brill, and W. Z. Ren, eds., Vol. 185, Progress in Astronautics and Aeronautics, AIAA, Reston, VA, 2000, pp. 335354. https://doi.org/10.2514/5.9781600866562.0335.0354

[3] T.A. Litzinger, Y.-J. Lee and C.-J. Tang, Experimental studies of nitramine/azide propellant combustion, in: Solid Propellant Chemistry, Combustion, and Motor Interior Ballistics, V. Yang, T. B. Brill, and W. Z. Ren, eds., Vol. 185, Progress in Astronautics and Aeronautics, AIAA, Reston, VA, 2000, pp. 355-379. https://doi.org/10.2514/5.9781600866562.0355.0379

[4] C.F. Melius, Thermochemical modeling: I. Application to decomposition of energetic materials, in: Chemistry and Physics of Energetic Materials, S. Bulusu, ed., Norwell, MA: Kluwer Academic, 1990, pp. 21-78.

[5] Y.-C. Liau and V.J. Yang, Analysis of RDX monopropellant combustion with two-phase subsurface reactions, Prop. Power 11 (1995), 727-739. https://doi.org/10.2514/3.23898

[6] J.E. Davidson and M.W. Beckstead, Twenty-Sixth Symposium (International) on Combustion, The Combustion Institute, Pittsburgh, 1996, pp. 1989-1996.

[7] J.E. Davidson and M.W. Beckstead, Modeling of HMX/GAP pseudo-propellant combustion, J. Prop. Power 13 (1997), 375-383. 
[8] K. Prasad, R.A. Yetter and M. Smooke, An eigenvalue method for computing the burning rates of RDX, Propellants Combust. Sci. Technol. 124 (1997), 35-82.

[9] K. Prasad, R.A. Yetter and M. Smooke, An eigenvalue method for computing the burning rates of HMX propellants, Combust. Flame 115 (1998), 406-416. https://doi.org/10.1016/S0010-2180(98)00009-1

[10] J.L. Gottfried, Laser-induced plasma chemistry of the explosive RDX with various metallic nanoparticles, Appl. Opt. 51 (2012), B13-B21. https://doi.org/10.1364/AO.51.000B13

[11] Y.-C. Liau, E.S. Kim and V. Yang, A comprehensive analysis of laser-induced ignition of RDX monopropellant, Combustion and Flame 126 (3) (2001), 1680-1698. https://doi.org/10.1016/S0010-2180(01)00281-4

[12] L. Qiu, X. Gong, X. Ju and H. Xiao, Substituent effect on the molecular stability, group interaction, detonation performance, and thermolysis mechanism of nitroaminosubstituted cyclopentanes and cyclohexanes, Science in China, Series B: Chemistry 51(12) (2008), 1231-1245. https://doi.org/10.1007/s11426-008-0141-1

[13] J. Yang, G. Wang, X. Gong, J. Zhang and Y.A. Wang, High-energy nitramine explosives: A design strategy from linear to cyclic to caged molecules, ACS Omega 3(8) (2018), 9739-9745. https://doi.org/10.1021/acsomega.8b00614

[14] C.A. Bayse and M. Jaffar, Bonding analysis of the effect of strain on trigger bonds in organic-cage energetic materials, Theoretical Chemistry Accounts 139(6) (2020), Art. No. 95. https://doi.org/10.1007/s00214-020-02604-0

[15] L. Türker, Hexahydro-1,3,5-trinitro-1,3,5-triazine-embedded cyclophanes, Journal of Molecular Structure: THEOCHEM. 530 (1-2) (2000), 131-136. https://doi.org/10.1016/S0166-1280(00)00320-1

[16] L. Türker, On the possibility of endohedrally helium-doped TEX - A DFT treatment, ZAAC 644(18) (2018), 1096-1102. https://doi.org/10.1002/zaac.201800183

[17] L. Türker, Destructive effect of magnesium and calcium atoms on TEX, Defence Technology 13(5) (2017), 367-375. https://doi.org/10.1016/j.dt.2017.02.001

[18] L. Türker and S. Variş, On the possibility of autoxidation of TEX - A DFT study, Propellants, Explosives, Pyrotechnics 40(1) (2015), 81-87. https://doi.org/10.1002/prep.201400114

[19] L. Türker, Nitrogen analogs of TEX - A computational study, Defence Technology 10(4) (2014), 328-333. https://doi.org/10.1016/j.dt.2014.07.001 
[20] Y. Bayat and V. Azizkhani, Synthesis of 4,10-dinitro-2,6,8,12-tetraoxa-4,10diazaisowurtzitane (TEX) using heteropolyacids as efficient and recyclable heterogeneous catalysts, Journal of Energetic Materials 30(3) (2012), 209-219. https://doi.org/10.1080/07370652.2011.562600

[21] U.R. Nair, R. Sivabalan, G.M. Gore, M. Geetha, S.N. Asthana and H. Singh, Hexanitrohexaazaisowurtzitane (CL-20) and CL-20-based formulations (review), Combustion, Explosion and Shock Waves 41 (2005), 121-132. https://doi.org/10.1007/s10573-005-0014-2

[22] L. Bao, P. Lv, T. Fei, Y. Liu, C. Sun and S. Pang, Crystal structure and explosive performance of a new CL-20/benzaldehyde cocrystal, Journal of Molecular Structure 1215 (2020), 128267. https://doi.org/10.1016/j.molstruc.2020.128267

[23] J.J.P. Stewart, Optimization of parameters for semiempirical methods I. Method, J. Comput. Chem. 10 (1989), 209-220. https://doi.org/10.1002/jcc.540100208

[24] J.J.P. Stewart, Optimization of parameters for semi empirical methods II. Application, $J$. Comput. Chem. 10 (1989), 221-264. https://doi.org/10.1002/jcc.540100209

[25] A.R. Leach, Molecular Modeling, Essex: Longman, 1997.

[26] P. Fletcher, Practical Methods of Optimization, New York: Wiley, 1990.

[27] W. Kohn and L. Sham, Self-consistent equations including exchange and correlation effects, Phys. Rev. 140 (1965), 1133-1138. https://doi.org/10.1103/PhysRev.140.A1133

[28] R.G. Parr and W. Yang, Density Functional Theory of Atoms and Molecules, London: Oxford University Press, 1989.

[29] C.J. Cramer, Essentials of Computational Chemistry, Chichester, West Sussex: Wiley, 2004.

[30] A.D. Becke, Density-functional exchange-energy approximation with correct asymptotic behavior, Phys. Rev. A 38 (1988), 3098-3100. https://doi.org/10.1103/PhysRevA.38.3098

[31] S.H. Vosko, L. Wilk and M. Nusair, Accurate spin-dependent electron liquid correlation energies for local spin density calculations: a critical analysis, Can. J. Phys. 58 (1980), 1200-1211. https://doi.org/10.1139/p80-159

[32] C. Lee, W. Yang and R.G. Parr, Development of the Colle-Salvetti correlation-energy formula into a functional of the electron density, Phys. Rev. B 37 (1988), 785-789. https://doi.org/10.1103/PhysRevB.37.785

[33] SPARTAN 06, Wavefunction Inc., Irvine CA, USA, 2006. 